\title{
Подготовка поверхностных и подземных вод для питьевого водоснабжения поселков в Арктической зоне
}

\author{
Ю.Л.СКолубович, НГАСУ (Сибстрин), Новосибирск \\ Е.Л.Войтов, НГАСУ (Сибстрин), Новосибирск \\ А.А.Цыба, НГАСУ (Сибстрин), Новосибирск \\ Д.В.Балчугов, НГАСУ (Сибстрин), Новосибирск \\ Д.Н.Монахов, НГАСУ (Сибстрин), Новосибирск
}

Новая стратегии развития Арктики до 2035 года закрепляет национальные интересы России в Арктике: обеспечение суверенитета и территориальной целостности, сохранение экосистемы Арктики, защита территории проживания коренных народов, сохранение Арктики как территории мира, а также высокий уровень жизни и благосостояния граждан России, живущих в Арктической зоне. Улучшение благоустройства северных поселений, развитие промышленных производств, перспективное освоение Северного морского пути и охрана северных рубежей России требует надёжного, бесперебойного круглогодичного снабжения населённых мест и объектов промышленности водой надлежащего качества и в достаточных объёмах. Неравномерное распределение посёлков и промпредприятий по обширной территории Арктической зоны РФ, большей частью их удалённость от централизованных систем водо- и энергоснабжения диктуют свои требования и особенности организации водоснабжения. В статье приводится новая технологическая схема подготовки питьевой воды на модульных водоочистных станциях в районах Крайнего Севера, а также результаты исследования работы пилотной установки в производственных условиях в Якутии.

Ключевые слова: Арктическая зона, криозона, экосистема, природно-климатические условия, благоустройство, модульные здания, технологическая схема, электролиз, электрокоагуляция, фильтрование, обеззараживание.

Preparation of Surface and Groundwater for Drinking Water Supply of Villages in the Arctic Zone

Yu.Skolubovich, NSUACE (Sibstrin), Novosibirsk

E.L.Voytov, NSUACE (Sibstrin), Novosibirsk

A.A.Tsyba, NSUACE (Sibstrin), Novosibirsk

D.V.Balchugov, NSUACE (Sibstrin), Novosibirsk

D.N.Monakhov, NSUACE (Sibstrin), Novosibirsk

The new Arctic development strategy until 2035 consolidates Russia's national interests in the Arctic: ensuring sovereignty and territorial integrity, preserving the Arctic ecosystem, protecting the territory of indigenous peoples, preserving the Arctic as a territory of the world, as well as a high standard of living and well-being of Russian citizens living in the Arctic zone. Improving the living environment of northern settlements, developing industrial production, deploying of the Northern Sea Route, and protecting the northern borders of Russia requires a reliable, uninterrupted year-round supply of populated places and industrial facilities with water of adequate quality and in sufficient quantities. The uneven distribution of villages and industrial enterprises over the vast territory of the Arctic zone of the Russian Federation, for the most part, their remoteness from centralized water and energy supply systems dictates its requirements and features of the organization of water supply. The article presents a new technological scheme of drinking water preparation at modular water treatment plants in the Far North, as well as the results of a study of the pilot plant in production conditions in Yakutia.

Keywords: Arctic zone, cryozone, ecosystem, climatic conditions, landscaping, modular buildings, technological scheme, electrolysis, electrocoagulation, filtering, disinfection.

Арктическая зона РФ (АЗ РФ) - это северная оконечность Европейской и Азиатской частей РФ. Площадь сухопутной части АЗ РФ составляет 18\% территории Российской Федерации - 3,1 млн кв. км. В арктическую зону РФ входят территории Мурманской области, Ненецкого, Чукотского и Ямало-Ненецкого автономных округов, Республики Коми, нескольких районов Республики Саха (Якутия), города Норильска, двух районов Красноярского края, муниципальных образований Архангельской области. Кроме того, к российской арктической зоне относится часть островов и архипелагов Северного Ледовитого океана [1].

На человека, находящегося в условиях Арктики и Антарктики, действует комплекс факторов: низкие температуры, колебания геомагнитного и электрического полей, атмосферного давления, космическая радиация в полярных широтах, нарушенный световой режим в периоды полярных дней и ночей, дефицит качественных продуктов питания, питьевой воды и т.п.

В последние десятилетия в развивающемся мире большое внимание уделяется улучшению водоснабжения, санитарии и гигиены, о чем свидетельствует провозглашённая $00 \mathrm{H}$ цель устойчивого развития, ориентированная на обеспечение к 2030 году «всеобщего и справедливого доступа к безопасной 
питьевой воде для всех». Однако обеспечение водопроводной питьевой водой недостаточно по её объёмам, что негативно влияет на здоровье населения арктических регионов. Кроме того, изменения климата и окружающей среды также представляют угрозу нормальному функционированию существующих систем системам водоснабжения и водоотведения, ухудшая доступность чистой воды [2].

В 2019 году на V Международном арктическом форуме в Санкт-Петербурге Президентом РФ В.В. Путиным анонсирована «Новая стратегии развития Арктики до 2035 года», которая чётко закрепляет национальные интересы России в этом регионе. Ключевые из них: обеспечение суверенитета и территориальной целостности, сохранение экосистемы Арктики, защита территории проживания коренных народов, сохранение Арктики как территории мира, а также высокий уровень жизни и благосостояния граждан России, живущих в Арктической зоне ${ }^{1}$. Арктика имеет важное военно-стратегическое значение для России: тут находится ряд важнейших предприятий оборонной промышленности.

Хозяйственно-экономические и природно-климатические условия в Северной климатической зоне Севера различны. Общими для районов зоны являются: суровый климат, повсеместное сплошное, прерывистое или островное залегание многолетнемёрзлых грунтов (криолитозона), длительные - по восемь-девять месяцев -зимы, снегозаносы, сильные ветры

${ }^{1}$ Путин В.В. Новая стратегии развития Арктики до 2035 года // Пленарное заседание Международного Арктического форума «Арктика - территория диалога». Санкт-Петербург, 09 апреля 2019 г. (источник: https://www.garant. ru/products/ipo/prime/doc/73606526/).

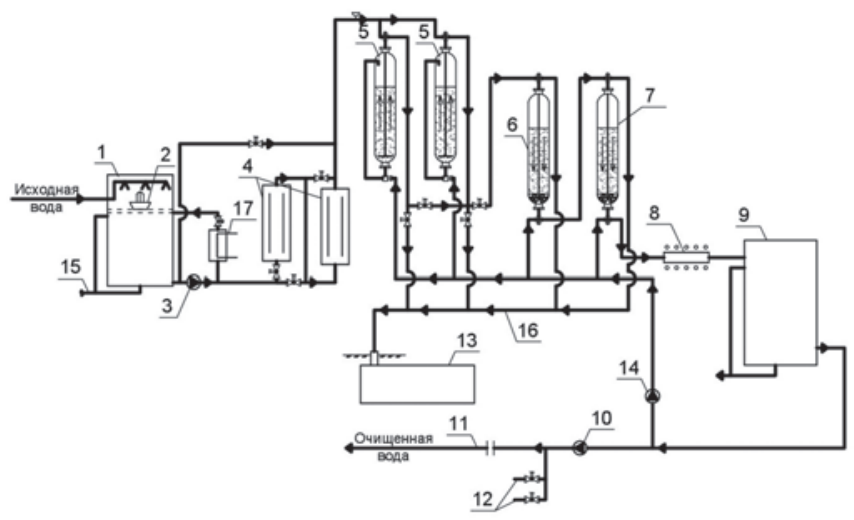

Рис. 1. Технологическая схема подготовки питьевой воды в районах Крайнего Севера: 1 - резервуар исходной воды; 2 уровнемер; 3 - подкачивающий насос; 4 - электрокоагуляторы; 5-напорные реакторы-осветлители; 6-фильтр первой ступени; 7 - фильтр второй ступени; 8 - УФ-стерилизатор; 9 - резервуар чистой воды (РЧВ); 10 - насос подачи воды потребителям; 11 - трубопровод подачи питьевой воды в сеть; 12 - краны заполнения бутылей; 13 - узел обработки промывной воды и осадка; 14 - промывной насос; 15 - переливной и дренажный трубопроводы резервуара исходной воды и РЧВ; 16 - трубопровод сброса промывной воды; 17 - бойлер (пурги), малый меженный и др. В криолитозоне реализованы крупномасштабные проекты по освоению уникальных природных богатств, по обживанию и урбанизации обширных территорий, строительству промышленных и энергообъектов, железнодорожных и автомагистралей, трубопроводов и т.д. [3-5].

Улучшение благоустройства северных поселений, развитие промышленных производств, перспективное освоение Северного морского пути и охрана северных рубежей России требуют надёжного, бесперебойного круглогодичного снабжения населённых мест и объектов промышленности водой надлежащего качества и в достаточных объёмах.

Неравномерное распределение посёлков и промпредприятий по обширной территории Арктической зоны РФ, их удалённость от централизованных систем водо- и, энергоснабжения (большей их части) диктует свои требования и особенности организации водоснабжения. Кроме того, в криолитозонах строительство зданий, в том числе станций водоподготовки, с фундаментами запрещено или невозможно. Также зачастую отсутствуют транспортные коммуникации и возможность доставки реагентов. Проблему водоснабжения малых населённых мест в условиях Крайнего Севера решает возведение модульных зданий и водоочистных станций в контейнерном исполнении. В отличие от стационарных сооружений модульные станции водоподготовки можно размещать прямо на грунте или на временном фундаменте. Их можно легко транспортировать вместе с передвижными котельными установками, строительными отрядами, колоннами, экспедициями. Снабжение водой модульной установки водоочистки осуществляется из реки и источников подземных вод, расположенных у населённых пунктов, вахтовых посёлков, предприятий, баз отдыха и других небольших объектов водоснабжения ${ }^{3}$.

Природные воды северных регионов и областей вечной мерзлоты характеризуются низкой температурой, высокой газонасыщенностью (метан, сероводород, углекислый газ), мутностью, цветностью, повышенным содержанием железа, марганца, иногда - бора, тяжёлых металлов, фенола и нефтепродуктов ${ }^{4}$. При проектировании водоочистных станций питьевого водоснабжения необходимо учитывать качество, особенности водоснабжения малых населённых мест в Арктической зоне России.

В Новосибирском государственном архитектурно строительном университете (Сибстрин) предложена технология подготовки питьевой воды для посёлков на водоочистных стациях в районах Крайнего Севера ${ }^{5}$ (рис. 1).

\footnotetext{
${ }^{2}$ Наименьший сток рек, наблюдающийся в период продолжительного сезонного стояния низких уровней воды в реке.

${ }^{3}$ Компания ВоДэКО. Модульные станции очистки воды (источник: https://vodeco.ru/stancii-ochistki-vody.html).

${ }^{4} 0$ состоянии окружающей среды РС(Я) в 2018 : Государственный доклад / Мин. экологии, природопользования и лесного хозяйства РС(Я). - Якутск : Сахаполиграфиздат, 2018. - 61 с.

${ }^{5}$ Пат. 2328454, Российская Федерация, МПК C 02 F 9/04, C 02 F 5/00 . Станция водоподготовки / Е.Л. Войтов, Ю.Л. Сколубович; Заявитель и патентообладатель - НГАСУ. № 2006107840; опубл. 10.07.2008; Бюл. № 19.
} 
Технологии очистки заключается в следующем.

Исходная вода подаётся в резервуар исходной воды (1) из источника водоснабжения.

Далее вода перекачивается подкачивающим насосом (3) и подаётся в блок электрохимической обработки, состоящий издвух электрокоагуляторов (4).

В электрокоагуляторах происходит медленное растворение алюминиевых электродов, образуются хлопья гидроксида алюминия, сорбирующие примеси железа, марганца и других загрязнений из очищаемой воды.

Затем вода под остаточным напором подается на блок фильтрации, состоящий из трёх ступеней фильтрования: осветления на реакторах-осветлителях (5), последовательного двухступенчатого фильтрования на фильтрах (6) и (7) соответственно. Часть воды по байпасной рециркуляционной линии возвращается во всасывающий трубопровод насоса (3) и вновь поступает в блок электрохимической обработки для накопления в системе соединений алюминия

Напорные реакторы-осветлители (P/O) (5) работают параллельно ${ }^{6}$. Р/О загружены песком мелкозернистой горелой породой. Крупность фракций загрузки реакторов и её высота определяются в результате технологического моделирования. Направление фильтрования в расширенном слое загрузки P/O - снизу вверх. Промывка загрузки - эжекторная со сбросом промывной воды на узел обработки промывной воды и осадка (13). Эжекторы располагаются под P/O. Водопесчаная пульпа подаётся в надзагрузочное пространство реакторов.

Из Р/О вода поступает на два последовательно соединённых фильтра. Выбор типа загрузок фильтров (цеолит, активированный уголь и др.) зависит от качества исходной воды и других местных условий. Направление фильтрования - нисходящее.

Переключение режимов фильтрация/промывка для реакторов-осветлителей (5) и фильтров (6), (7) выполняется посредством смены положения верхних электроприводных клапанов.

Промывка фильттров осуществляется чистой водой в направлении снизу вверх с помощью промывного насоса (14). Сброс промывных вод также производится в узел обработки промывной воды и осадка (13).

Очищенная вода после блока фильтрования подвергается обеззараживанию с помощью УФ-стерилизатора (8) и поступает в резервуар чистой воды (РЧВ) (9), оборудованный переливным и дренажным трубопроводами (15). Возможна подача воды в разводящую сеть потребителя насосом (10) по трубопроводу (11) и её бутылирование через водоразборные краны (12).

В связи с низкими температурами в отдельные периоды года возможен предварительный подогрев исходной воды

6 Пат. 181324, Российская Федерация, МПК CO2F 3/10, CO2F 3/26, CO2F 1/52 Устройство для очистки воды / Е.Л. Войтов, Ю.Л. Сколубович, А.Ю. Сколубович; Заявитель и патентообладатель НГАСУ. № 2017144382; Опубл. 10.07.2017; Бюл. № 19.

7 Пат. 2328454, Российская Федерация, МПК С 02 F 9/04, C 02 F 5/00 . Станция водоподготовки /Е.Л.Войтов, Ю.Л.Сколубович; Заявитель и патентообладатель НГАСУ. № 2006107840; опубл. 10.07.2008; Бюл. № 19.

для активизации процесса электрокоагуляции с помощью бойлера (17).

Предварительные экспериментальные исследования новой технологии очистки проведены на пилотной установке сооружений водоподготовки в производственных условиях в селе Хоро (Якутия) на натуральной природной воде реки Вилюй.

Фото пилотной установки и ее узла электрокоагуляции представлены на рисунке 2.

Осреднённые показатели качества исходной речной и очищенной воды за характерный суточный цикл работы пилотной установки представлены в таблице 1.

Таблица 1. Качественные показатели исходной, очищенной воды и требования к качеству очищенной воды

\begin{tabular}{|c|c|c|c|c|c|}
\hline Поз. & $\begin{array}{l}\text { Наименование } \\
\text { показателя }\end{array}$ & Ед. изм. & $\begin{array}{c}\text { Исходная } \\
\text { вода }\end{array}$ & $\begin{array}{l}\text { Очищен- } \\
\text { ная вода }\end{array}$ & $\begin{array}{c}\text { Требования к очи- } \\
\text { щенной воде } \\
\text { (СанПин 2.1.4.1074 } \\
\text { 01) }\end{array}$ \\
\hline 1 & $\begin{array}{l}\text { Водородный } \\
\text { показатель рH }\end{array}$ & $\begin{array}{c}\text { единицы } \\
\text { pH }\end{array}$ & 7,82 & 7,82 & $6-9$ \\
\hline 2 & Мутность & $\mathrm{Mr} / \Omega$ & до 100 & до 100 & 1,5 \\
\hline 3 & $\begin{array}{l}\text { Окисляемость } \\
\text { преманганатная }\end{array}$ & $\mathrm{Mr} \mathrm{O}_{2} / \Omega$ & 7 & 7 & $\leq 5$ \\
\hline 4 & $\begin{array}{l}\text { Жёсткость } \\
\text { общая }\end{array}$ & МГ-эКВ/ת & 5,75 & 5,75 & 5,5 \\
\hline 5 & Аммиак & $\mathrm{Mr} / \Omega$ & 2,35 & 2,35 & 1,6 \\
\hline 6 & Марганец & $\mathrm{Mr} / \Omega$ & 0,25 & 0,25 & 0,1 \\
\hline 7 & Щёлочность & мГ-эКВ/л & 5,6 & 5,6 & 5,2 \\
\hline 8 & Кремний & $\mathrm{Mr} / \Omega$ & 14,6 & 14,6 & 4 \\
\hline 9 & Запах & баллы & 2 & 2 & 1 \\
\hline 10 & Сульфат-ион & $\mathrm{Mr} / \Omega$ & $40-60$ & $40-60$ & $50-60$ \\
\hline 11 & Хлориды & $\mathrm{Mr} / \Omega$ & $30-40$ & $30-40$ & $80-85$ \\
\hline 12 & Железо общее & $\mathrm{Mr} / \Omega$ & 4,59 & 4,59 & 0,3 \\
\hline 13 & Цветность & град. & до 200 & до 200 & 20 \\
\hline 14 & OMY & КОЕ/мл & 27 & 19 & $\leq 50$ \\
\hline 15 & Колиформн. бакт. & $\begin{array}{c}\text { KOE/ } \\
100 \text { мл }\end{array}$ & 23 & отсутст. & отсутст. \\
\hline 16 & $\begin{array}{l}\text { Термотолер. } \\
\text { бакт. }\end{array}$ & $\begin{array}{l}\mathrm{KOE/} \\
100 \text { мл }\end{array}$ & $\begin{array}{c}\text { не } \\
\text { обнаруж. }\end{array}$ & отсутст. & отсутст. \\
\hline
\end{tabular}

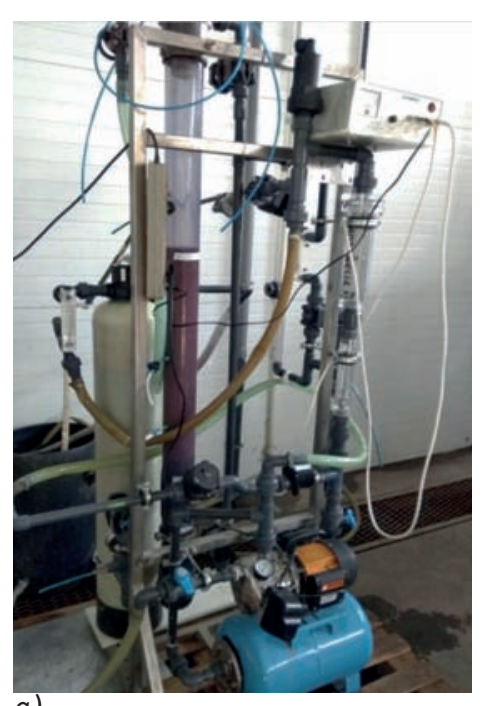

a)

Рис. 2. Пилотная установка сооружений водоподготовки: а) общий вид; б) узел электрокоагулящии

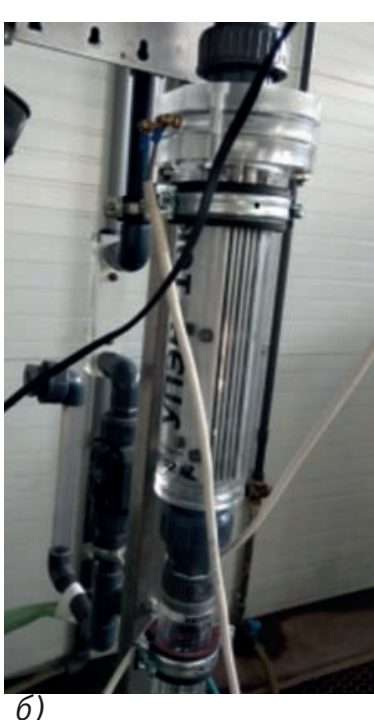

б) 
Как показали результаты оценки эффективности очистки природной воды, качество очищенной воды по физическим, химическим и бактериологическим свойствам отвечает нормативным требованиям, предъявляемым СанПин 2.1.4.1074-01 к воде для питьевых целей ${ }^{8}$.

\section{***}

1. Мировым сообществом уделяется большое внимание сохранению экосистемы Арктики, защите территории проживания коренных народов, сохранению Арктики как территории мира, а также обеспечению высокого уровня жизни и благосостояния населения Арктической зоны.

2. Обеспечение водопроводной питьевой водой недостаточно, что негативно влияет на здоровье населения арктических регионов. Кроме того, изменения климата и окружающей среды представляют угрозу существующим системам водоснабжения и водоотведения, уменьшая доступность чистой воды.

3. При проектировании водоочистных станций питьевого водоснабжения необходимо учитывать качество воды из природных источников и особенности водоснабжения малых населенных мест в Арктической зоне России.

4. Предварительные исследования разработанной НГАСУ (Сибстрин) технологии подготовки питьевой воды показали, что она обеспечивает качество питьевой воды, отвечающее нормативным требованиям, минимизирует затраты по строительству и эксплуатации станций водоподготовки.

5. Для выбора и обоснования оптимальных конструктивных и технологических параметров оборудования в условиях Крайнего Севера, разработки методов утилизации промывной воды и водопроводного осадка требуется проведение специальных исследований.

\section{Лuтература}

1. Каменецкий, М.И. Пространственное освоение сухопутных территорий арктической зоны РФ как сфера специализированной деятельности строительного комплекса / М.И. Каменецкий // Научные труды института народнохозяйственного прогнозирования РАН. - 2015. - С. 402-417.

2. Хеннесси, Томас В. Инициатива Арктического совета для улучшения здоровья в арктическом регионе путём обеспечения доступа к бытовым системам водоснабжения и канализации / Томас В. Хеннеси // Проблемы сохранения здоровья и обеспечения санитарно-эпидемиологического благополучия населения в Арктике : Материалы научно-практической конференции с международным участием. 5-6 октября 2017 г. - СПб : Северо-западный научный центр гигиены и общественного здоровья, 2017. - С. 251-252.

${ }^{8}$ СанПин 2.1.4.1074-01. Питьевая вода. Гигиенические требования к качеству воды централизованных систем питьевого водоснабжения. Контроль качества. Санитарно-эпидемиологические правила и нормативы. - М.: Федеральный центр госсанэпидемнадзора Минздрава России, 2002. - 103 с.
3. Вдовин, Ю.И. Водозаборно-очистные сооружения в системах водоснабжения в криолитозоне России / Ю.И. Вдовин, Н.С. Вишневская. - М. : Изд. РУДН, 2007. - 236 с.

4. Войтов, Е.Л. Подготовка питьевой воды из поверхностных источников с повышенным природным и антропогенным загрязнением / Е.Л. Войтов, Ю.Л. Сколубович. - Новосибирск: НГАСУ (Сибстрин), 2010. - 216 с.

5. Войтов Е.Л. Подготовка питьевой воды из подземных источников в экологически неблагоприятных регионах / Е.Л. Войтов, Ю.Л. Сколубович. - Новосибирск : НГАСУ (Сибстрин), 2010. - 220 c.

\section{References}

1. M.I. Kamenetskii Prostranstvennoe osvoenie sukhoputnykh territorii arkticheskoi zony RF kak sfera spetsializirovannoi deyatel'nosti stroitel'nogo kompleksa [Spatial development of land areas of the Arctic zone of the Russian Federation as a sphere of specialized activity of the building complex] In: Nauchnye trudy instituta narodnokhozyaistvennogo prognozirovaniya RAN [Scientific works of the Institute of National Economic Forecasting of the Russian Academy of Sciences], 2015, pp. 402-417. (In Russ.)

2. Khennessi Tomas V. Initsiativa Arkticheskogo soveta dlya uluchsheniya zdorov'ya $v$ arkticheskom regione putem obespecheniya dostupa k bytovym sistemam vodosnabzheniya i kanalizatsii [Initiative of the Arctic Council to improve health in the Arctic region by providing access to domestic water supply and sewerage systems]. In: Problemy sokhraneniya zdorov'ya i obespecheniya sanitarno-epidemiologicheskogo blagopoluchiya naseleniya $v$ Arktike: Materialy nauchnoprakticheskoi konferentsii s mezhdunarodnym uchastiem. 5-6 oktyabrya $2017 \mathrm{~g}$. [Problems of preserving health and ensuring sanitary and epidemiological well-being of the population in the Arctic: Materials of a scientific-practical conference with international participation. 5-6 0ctober 2017]. Saint Petersburg, North-Western Scientific Center of Hygiene and Public Health, 2017, pp. 251-252.

3. Vdovin Yu.I., Vishnevskaya N.S. Vodozaborno-ochistnye sooruzheniya $v$ sistemakh vodo-snabzheniya $v$ kriolitozone Rossii [Water intake and treatment facilities in water supply systems in the permafrost zone of Russia]. Moscow, RUDN Publ., 2007, 236 p.

4. Voitov E.L., Skolubovich Yu.L. Podgotovka pit'evoi vody iz poverkhnostnykh istochnikov s povyshennym prirodnym i antropogennym zagryazneniem [Preparation of drinking water from surface sources with increased natural and anthropogenic pollution]. Novosibirsk, NGASU (Sibstrin) Publ., 2010, 216 p.

5. Voitov E.L., Skolubovich Yu.L. Podgotovka pit'evoi vody iz podzemnykh istochnikov $v$ ekologicheski neblagopriyatnykh regionakh [Preparation of drinking water from underground sources in ecologically unfavorable regions]. Novosibirsk, NGASU (Sibstrin) Publ., 2010, 220 p. 
Сколубович Юрий Леонидович (Новосибирск). Доктор технических наук, профессор, член-корреспондент РААСН. Ректор ФГБУ В0 «Новосибирский государственный архитектурно-строительный университет» (Сибстрин)» [630008, Новосибирск, ул. Ленинградская, 113. НГАСУ (Сибстрин)]. Эл. почта: rector@sibstrin.ru.

Войтов Евгений Леонидович (Новосибирск). Доктор технических наук, доцент, советник РААСН. Профессор кафедры «Водоснабжение и водоотведение» ФГБУ В0 «Новосибирский государственный архитектурно-строительный университет (Сибстрин)» [630008, Новосибирск, ул. Ленинградская 113. НГАСУ (Сибстрин)]. Эл. почта: voitovel@ya.ru.

Цыба Анна Александровна (Новосибирск). Аспирант кафедры «Водоснабжение и водоотведение» ФГБУ В0 «Новосибирский государственный архитектурно-строительный университет» (Сибстрин)» [630008, Новосибирск, ул. Ленинградская 113. НГАСУ (Сибстрин)]. Эл. почта: anyuta.tsyba@ yandex.ru.

Балчугов Денис Валерьевич (Новосибирск). Аспирант кафедры «Водоснабжение и водоотведение» ФГБОУ В0 «Новосибирский государственный архитектурно-строительный университет (Сибстрин)» [630008, Новосибирск, ул. Ленинградская 113. НГАСУ (Сибстрин)]. Эл. почта: bal@sibstrin.ru.

Монахов Дмитрий Николаевич (Новосибирск). Магистрант кафедры «Водоснабжение и водоотведение» ФГБОУ В0 «Новосибирский государственный архитектурно-строительный университет (Сибстрин)» [630008, Новосибирск, ул. Ленинградская, 113. НГАСУ (Сибстрин)]. Эл. почта: rad-crusher@yandex.ru.

Skolubovich Yury L. (Novosibirsk). Doctor of Technical Sciences, Professor, Corresponding Member of RAACS. Rector of the Novosibirsk State University of Architecture and Civil Engineering [113 Leningradskaya St, Novosibirsk, 630008. NGASU (Sibstrin)]. E-mail: rector@sibstrin.ru.

Evgeny Leonidovich V. (Novosibirsk). Doctor of Technical Sciences, Associate Professor, Advisor of RAACS. Professor of the Water Supply and Sewerage Department at the Novosibirsk State University of Architecture and Civil Engineering [113 Leningradskaya St, Novosibirsk, 630008. NGASU (Sibstrin)]. E-mail: voitovel@ya.ru.

Tsyba Anna A. (Novosibirsk). Postgraduate of the Water Supply and Sewerage Department at the Novosibirsk State University of Architecture and Civil Engineering [113 Leningradskaya St, Novosibirsk, 630008. NGASU (Sibstrin)]. E-mail: anyuta.tsyba@ yandex.ru.

Balchugov Denis V. (Novosibirsk). Post-graduate student of the Water Supply and Sewerage Department at Novosibirsk State University of Architecture and Civil Engineering [113 Leningradskaya St., Novosibirsk, 630008. NGASU (Sibstrin)]. E-mail: bal@ sibstrin.ru.

Monakhov Dmitry N. (Novosibirsk). Master student of the Department of Water Supply and Wastewater Disposal at Novosibirsk State University of Architecture and Civil Engineering [113 Leningradskaya St, Novosibirsk, 630008. NGASU (Sibstrin)]. E-mail: rad-crusher@yandex.ru. 